\title{
Experimental Research of the Weakening of the Fuselage Skin by RFSSW Single Row Joints
}

\author{
Andrzej Kubit ${ }^{*}$, Magdalena Bucior', Rafał Kluz', \\ Wojciech Bochnowski², Ryszard Perłowski' \\ 1 Rzeszow University of Technology, Faculty of Mechanical Engineering and Aeronautics, al. Powstańców \\ Warszawy 8, 35-959 Rzeszów, Poland \\ 2 Department of Mathematics and Natural Sciences, University of Rzeszow, Rzeszów, Poland \\ * Corresponding author's e-mail: akubit@prz.edu.pl
}

\begin{abstract}
The paper presents the results of experimental investigations, the aim of which was to determine the degree of weakening of skin sheet of the thin-walled structure through a single-row welded joints made by Refill Friction Stir Spot Welding (RFSSW) technology. At the beginning, a short metallographic analysis of the weld was carried out, defining the characteristic areas of the microstructure. Then, comparative tests were carried out on the thin-walled structure sample in the form of a single-row skin-stringer joint. The structures made with the discussed technology of welding were compared with the traditionally joined structure by riveting. It has been shown that in the case of the welded structure, the skin sheet is weakened by more than $6 \%$ to a lesser extent than in the case of riveted. However, it was shown that the cracking path in the tensiled welded sheet runs along an unpredictable path, deviating from the line marked by the welds' row. While in the case of riveted joint the cracking propagation along the row of rivets was revealed. The analyzes of fracture surfaces for both cases using scanning electron microscopy were also undertaken, thus undertaking preliminary considerations on the mechanism of fracture.
\end{abstract}

Keywords: RFSSW, welding, thin-walled structures, pressurization, microstructure analysis

\section{INTRODUCTION}

Looking at the products of the leading companies from the aviation industry, both the construction of aircrafts and helicopters can be seen two major trends in the construction of fuselages. The first of them, seeming to be more forward-looking, is the use of fibre-reinforced polymer composites mainly in the form of laminates. Composites are characterized by high fatigue strength [1-3]. The elements of the structure are made on the basis of pre-impregnants in autoclave processes, because it is currently a technology that ensures the highest quality of the structure, among others.

The second group of materials used in the construction of thin-walled stiffened structures in aviation are light metal alloys, mainly aluminum, and in some nodes of the structure also titanium [4-6].
Despite the use of traditional materials such as aluminum alloys from the 20xx and 70xx families, aerospace manufacturers are intensively developing machining, shaping and joining technologies in order to constantly search for the possibility of reducing the weight of products while maintaining durability. In general, metals are today a better known group of materials, thanks to which it is possible to accurately predict their behavior in the full spectrum of loads occurring in operating processes.

Thin-walled structures are most often manufactured in such a way that the stiffening elements (stringers, frames) are joined with the skin using rivets [7-9]. This is the most traditional method, currently the most widespread, which, however, is characterized by high time-consuming technological process. An important disadvantage of this solution is the fact that the rivet holes weaken the 
structures, constitute notches causing local stress concentration [10], which is dangerous especially from the point of view of fatigue strength. Another problem is the increase in mass caused by the introduction of a large number of rivets into the construction. Figure 1 presents the classic and still most commonly used [8] structure of the skin joint by riveting with the stringer.

Although riveted structures are well known and perform well, there is an indisputable need for research and development of new joining technologies that could potentially lead to a reduction in the mass of the structure while maintaining the required strength properties. Therefore, the topic discussed in the present study regarding the properties of joints welded with the RFSSW method for use in the construction of thin-walled structures seems to be up-to-date and fully justified.

This paper presents the results of experimental investigations aimed at determining the degree of weakening of the skin sheet by RFSSW welds. The weakening of the skin was determined based on the phenomenon of presurization. This is part of a wider research cycle aimed at providing an initial answer to the question whether the RFSSW welding technology can be used as an alternative to the traditionally used riveting in the construction of thin-walled stiffened structures. The issue concerns a single-row skin-stringer joint.

The basic features of RFSSW welding technology are listed below in comparison to riveting [11]:

- there is no need to drill holes in the joined elements;

- rivet holes being stress concentrators are eliminated;

- no additional elements are used, such as rivets that raise the weight of the structure;

- the strength of the RFSSW welded joint can exceed the strength of the rivet joint;

- rivets as elements with a different electrochemical potential cause greater susceptibility to corrosion, therefore in the welded joint without introducing additional material, the structure's corrosion is reduced;

- welded joint does not introduce any elements protruding beyond the welded surfaces of sheet metal, whereas in the case of rivets, usually we deal with heads of rivets protruding above surfaces.

Despite the unquestionable advantages of RFSSW technology in relation to riveting, this technology being relatively new is not yet fully understood.

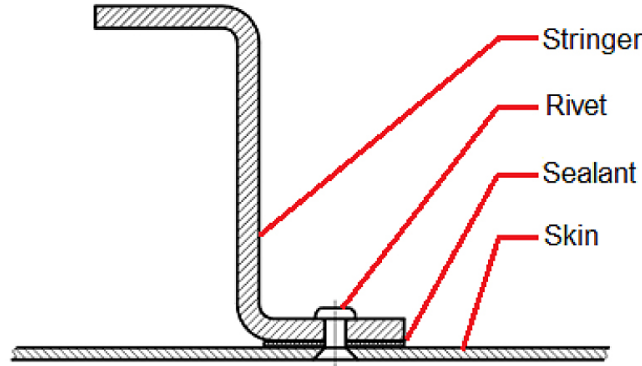

Fig. 1. Typical construction of thin-walled stiffened structure made by riveting

When considering thin-walled structures on the example of aircraft structures, it should be noted that in air transport, pressurized fuselages are commonly used. They allow a flight above $3000 \mathrm{~m}$, where there is a significant pressure drop compared to the prevailing earth. In order to maintain the pressure in the cabin of the aircraft, which will not have a negative impact on the well-being and health of the crew of aircraft and passengers, the so-called the phenomenon of presurization [12]. It consists in maintaining the required pressure (and temperature) inside the fuselage, regardless of the conditions prevailing outside. This means that with thinned pressure, which prevails at higher altitudes, the pressure inside the aircraft fuselage is higher than the ambient pressure, which is schematically shown in Fig. 2a. As a result, stress acts on the skin as the walls of the pressure vessel (Fig. 2b).

This phenomenon causes that the skin sheet is cyclically stretched with each take-off cycle [12-14].

The described phenomenon translates into the fact that the fuselage of such an aircraft works de facto as a pressure vessel. The pressure is increased with each aircraft takeoff cycle, hence the fuselage structure is cyclically drawn from the inside. This problem has been carefully described and subjected to a series of complex experimental investigations after a series of plane crashes De Havilland Comet [12, 15]. It was the first passenger jet airplane that was produced serially by the British company de Havilland. This aircraft had an erroneous construction of the pressure booth. As the series of tests showed, the cycles of loads associated with pressure changes in the interior of the fuselage, caused accumulation of stresses in the area of rectangular windows by stress accumulation in the area of rivet holes. This led to fatigue of the skin material, which resulted in the destruction of the fuselage structure during the flight [15]. 
a)

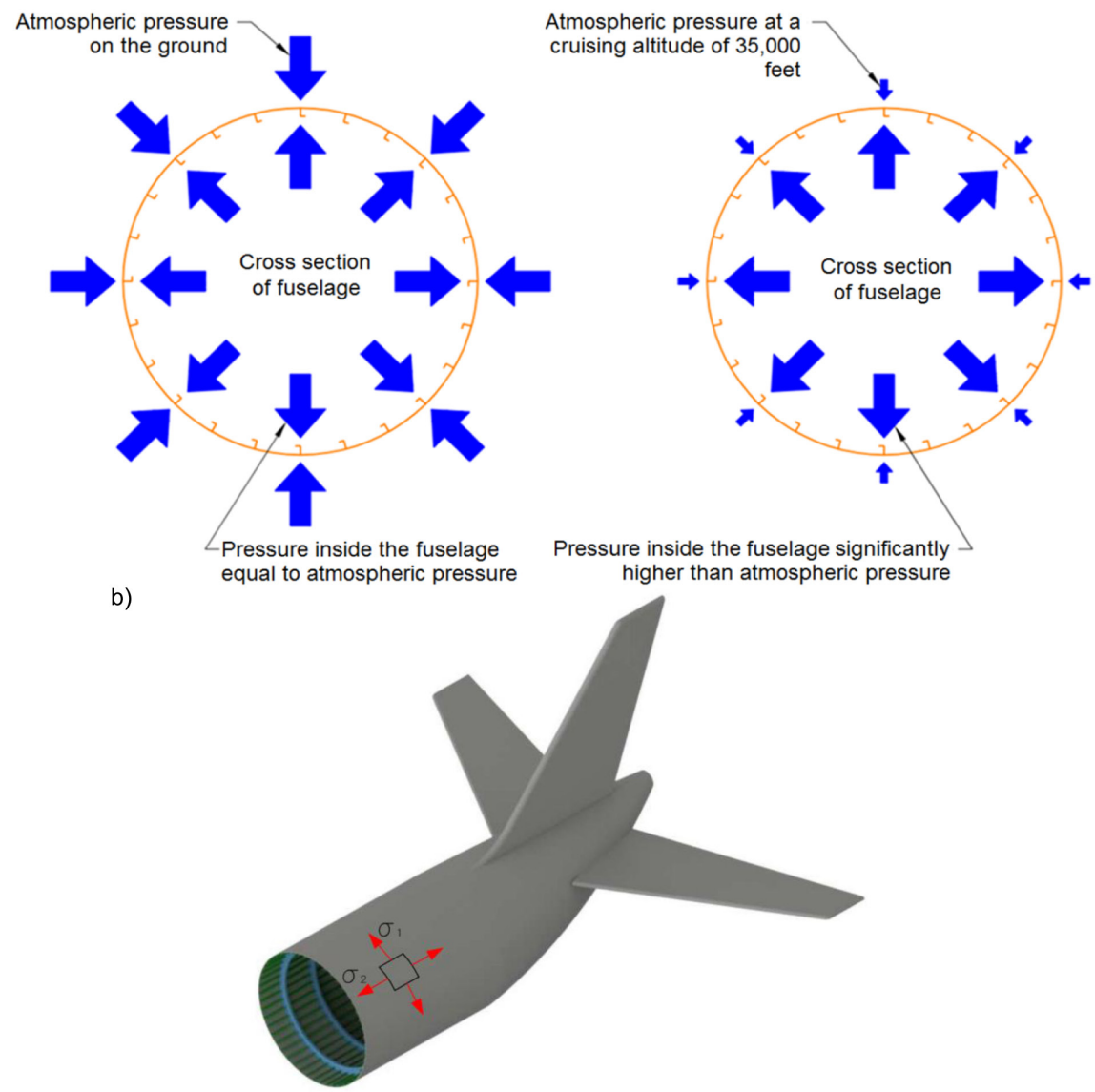

Fig. 2. The phenomenon of presurization presented on the example of the fuselage of the aircraft; diagram of the cross section of fuselage structure stretching due to pressure difference (a), stress distribution in the skin (b)

In the case of the skin-stringer rivet joint, the phenomenon of stress concentration in the area of rivet holes is well known. However, in the case of RFSSW welded joints, although holes are not made here, there is a significant interference in the structure of the material, e.g. through the influence of heat in the welding process. Thus, the heat affected zone as well as the thermo-mechanically affected zone weaken the skin sheet.

\section{MATERIALS AND METHOD}

A single-row skin-stringer joint was tested. Both of these elements are made of Alclad 7075-T6 aluminum alloy. The main alloys additions of this material are zinc, magnesium and copper. This alloy is characterized by high static and fatigue strength, it is difficult to plastically forming, because the yield point is close to the tensile strength [17]. In addition, the material is difficult to weld and has a relatively low corrosion resistance [17]. The basic feature that is high strength while maintaining low weight makes it a material commonly used in the construction of aircraft structures. Table 1 lists the chemical composition of the used material.

Considering the joint between the skin and the stringer, the tests assumed sheets with thicknesses of $0.8 \mathrm{~mm}$ (corresponding to the skin) and $1.6 \mathrm{~mm}$ (corresponding to the stringer).

The mechanical properties in the static tensile test according to ISO 6892-1 standard [18] were determined for the used sheets. The measurements were made for three different directions in relation to the rolling direction of the sheet, i.e. $0^{\circ}, 45^{\circ}$ and $90^{\circ}$. For each of the directions five repetitions were made, the average results are summarized in Table 2.

Microstructural examination of the RFSSW samples was carried out using a Nikon Epiphot 300 light microscope as well as a Hitachi S3400N scanning electron microscope.

Experimental studies were carried out, in which the tensile strength of the skin sheet with a riveted and welded stringer was compared. 
Table 1. Chemical composition of 7075-T6 aluminium alloy (wt.\%)

\begin{tabular}{|c|c|c|c|c|c|c|c|c|c|}
\hline $\mathrm{Si}$ & $\mathrm{Fe}$ & $\mathrm{Cu}$ & $\mathrm{Mn}$ & $\mathrm{Mg}$ & $\mathrm{Cr}$ & $\mathrm{Zn}$ & $\mathrm{Ti}$ & $\begin{array}{c}\text { Other } \\
\text { impurities }\end{array}$ & $\mathrm{Al}$ \\
\hline 0.40 & 0.50 & $1.2-2.0$ & 0.30 & $2.1-2.9$ & $0.18-0.28$ & $5.1-6.1$ & 0.30 & $\max 0.15$ & rest \\
\hline
\end{tabular}

Table 2. Basic mechanical properties of Alclad 7075-T6 aluminium alloy

\begin{tabular}{|c|c|c|c|}
\hline Parameter & Ultimate tensile stress $\mathrm{R}_{\mathrm{m}}, \mathrm{MPa}$ & Yield stress $\mathrm{R}_{\mathrm{p} 0.2}, \mathrm{MPa}$ & Elongation at failure $\mathrm{A}, \%$ \\
\hline Value & 482.6 & 413.7 & 7 \\
\hline
\end{tabular}

Both variants were compared with the tensile result for a uniform sheet of 7075-T6 alloy, thus obtaining information on the degree of weakening of the skin sheet both riveted and welded with RFSSW technology.

The riveting process was conducted in universal riveting machine. The refill friction stir spot welding process was conducted using an RPS100 spot welder by Harms \& Wende GmbH \& Co KG (Hamburg, Germany) at Belgian Welding Institute (Zwijnaarde - Gent, Belgium). The RFSSW welding process can be briefly divided into four main stages: touchdown, plunging, refilling and tool retracting, which were in detail described in the recent paper of authors [17]. The parameters of the RFSSW were as follow: spindle rotation speed $2000 \mathrm{rpm}$, plunge time $0.5 \mathrm{~s}$, stirring dwell time $1.5 \mathrm{~s}$, tool retract time $0.5 \mathrm{~s}$ and plunge depth $1.6 \mathrm{~mm}$. The diameter of the welds was equal of $9 \mathrm{~mm}$.

The tests were carried out for the samples shown in Figure 3. For the variant riveted using the rivet spacing $\mathrm{p}=23.5 \mathrm{~mm}$, six joint points were obtained, while for the welded variant using the weld spacing $\mathrm{p}=29.5 \mathrm{~mm}$ five welds were obtained.

The tests were carried out on a Zwick/Roell Z100 testing machine using a test speed of 200 $\mathrm{N} / \mathrm{s}$. The testing of the welded sample was carried out after a natural aging process lasting six months.

\section{RESULTS}

First, the microstructure of the connection was analyzed. Fig. 4 presents a microscope view of the weld with the border zone enlargement between the characteristic areas of the joint. The following zones are seen: stir zone (SZ), thermomechanically affected zone (TMAZ) and heat affected zone (HAZ). The stir zone is characterized by significant grain refinement, with respect to the base material, the grain size changes rapidly in the TMAZ zone. Due to the abrupt change in grain size, a structural notch is formed which

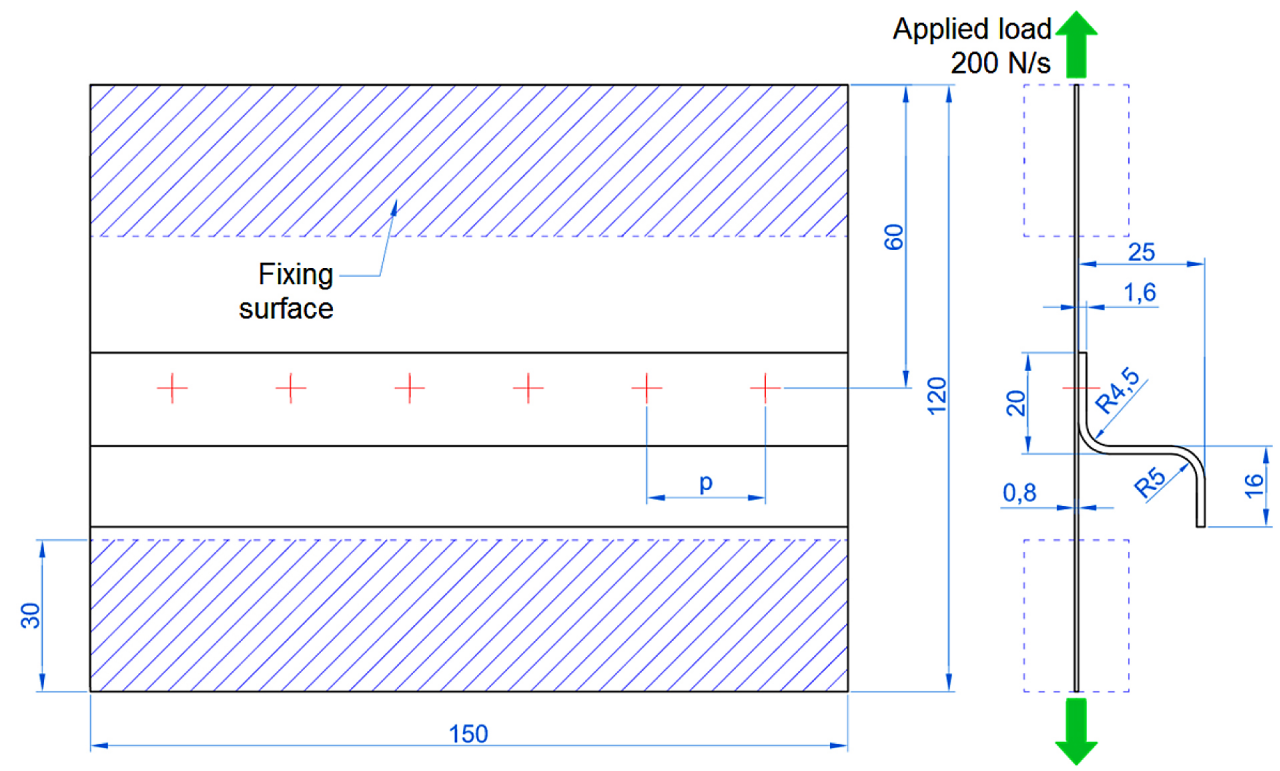

Fig. 3. Dimensions and method of loading the sample for weakening tests of the skin sheet 
may cause the material to weaken. In addition, in the HAZ zone due to the heat, the alloy was derived from the T6 state, thus the material was weakened. In connection with the above, it can be expected that the stretched sheet with a row of welds will crack along the circumference of the welds, but also the cracking can propagate through the zone of heat influence towards the base material.

The graph (Fig. 5) presents the results of the weakening tests of the sheet in the riveted and welded joint. Strength results were compared with the strength of a uniform sheet of aluminum 7075-T6. As shown in both variants of the joint, the sheet is weakened. In the case of weakening with rivet holes, the strength of the skin sheet decreased by $11.7 \%$, while in the case of the welded variant, the heat affected zone led to a $5.4 \%$ reduction in the strength of the sheet.

In the case of a riveted joint, the sheet weakened by the rivet holes is destroyed in the line of the rivets (Fig. 6a). However, in the case of a welded joint, the nature of the cracking is different from riveted. A cracking path is visible here, which propagates from the weld edge obliquely in relation to the row of welds towards the base material (Fig. 6b). This characteristic way of cracking is characterized by the omission of the area of the extreme weld in the crack propagation process (on the left side of Fig. 6b).

The difference in the cracking of the presented variants is caused by the accumulation of stresses at the edges of the rivet holes, which forces the course of cracking along the line of rivets.

The characteristic direction of cracking of the welded variant, devoid of openings, is typical for sliding ductile fracture. In addition to the lack of openings, another phenomenon affecting the different nature of cracking, the structural properties of the metal are changed through the heat affected zone. Due to this, locally, around

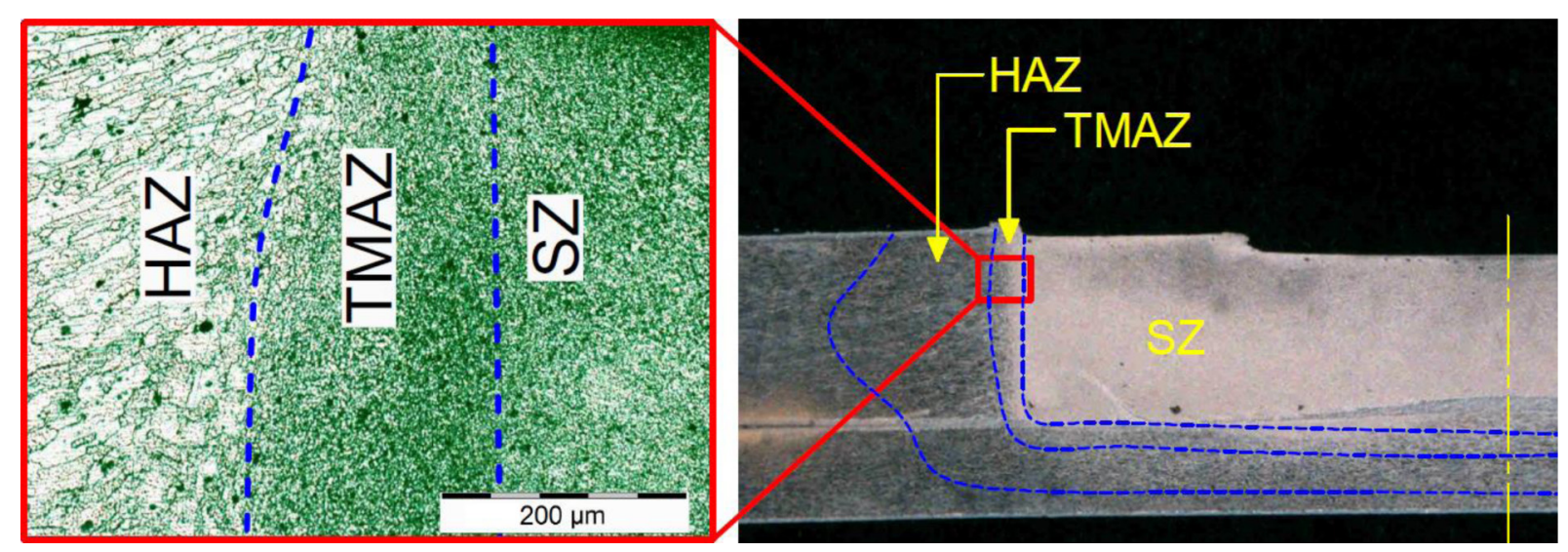

Fig. 4. View of the microstructure of the welded joint specifying the characteristic areas

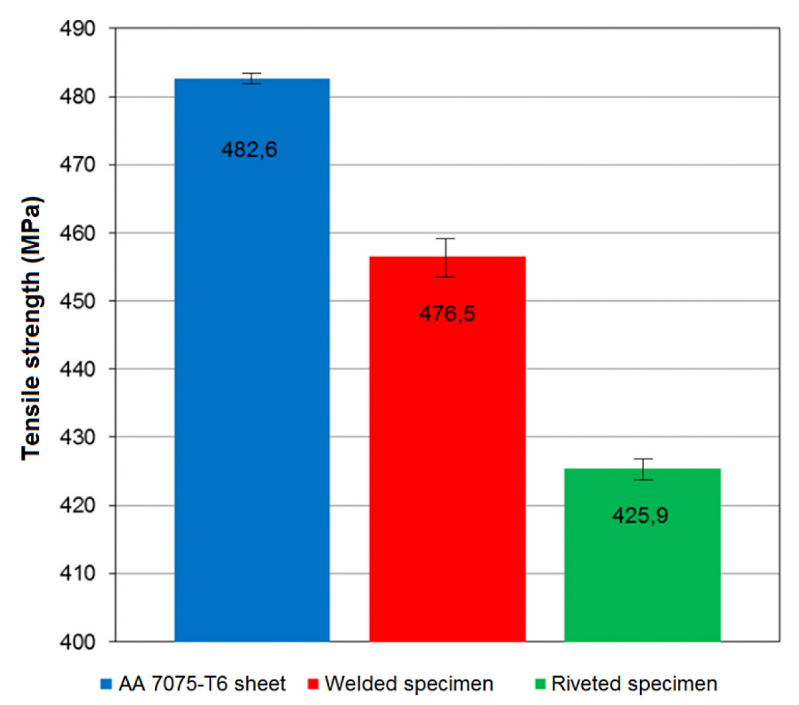

Fig. 5. The results of tests of tensile strength of the skin sheets weakened by rivets, welds and uniform sheet 

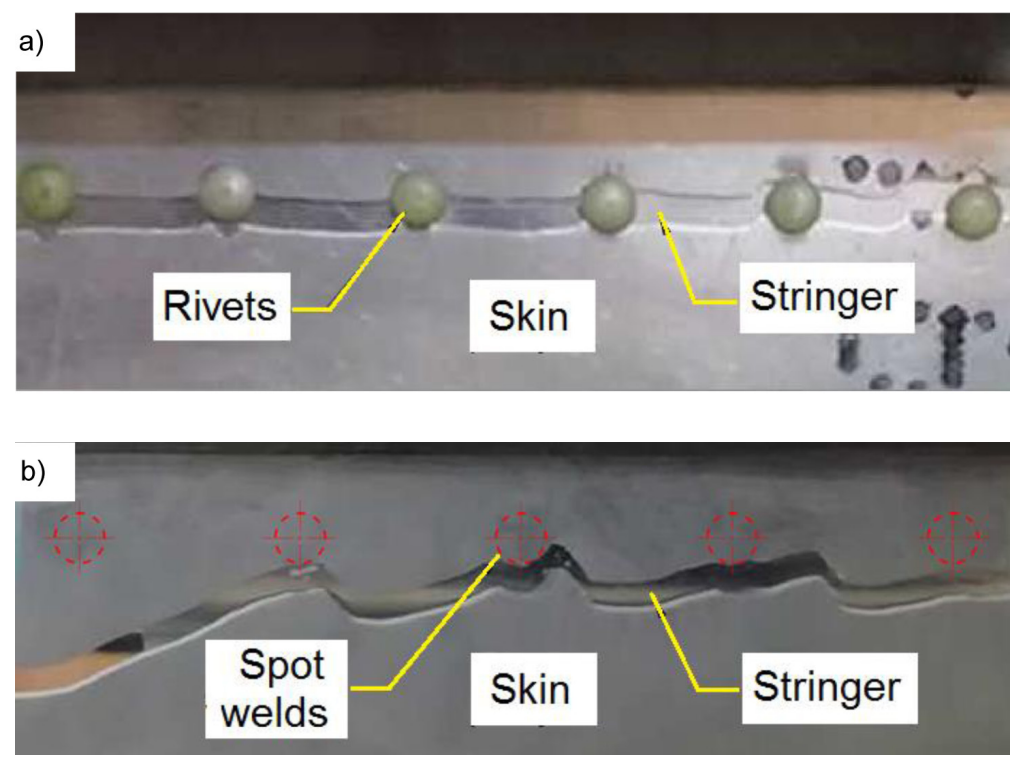

Fig. 6. View of cracked samples with visible cracking path associated with joints:

(a) for riveted sample, (b) for welded sample

the welds, the material has different properties than the base material, hence different behavior in the static tensile test.

In the case of a riveted joint, the cracking path is predictable and, as expected, the sheet has been torn along the row of rivets. However, the sheet joined by welding showed an unpredictable way of cracking, because the extreme weld was omitted, and thus the cracking path was directed to the base material. This is an unfavorable phenomenon, because such a method of cracking makes it impossible to predict the propagation process of cracks in the structure.

Turning to the analysis of breakthroughs, on the basis of their microscopic images (SEM) it is possible to show differences in the mechanism of destruction of both variants. In the case of a riveted sample, it can be seen that under the influence of stress concentration at the edge of the openings, the plasticization of the material started, and thus the plastic state widened from the axis of the hole (Fig. 7). The plastic deformation progressing from the edge of the hole led to the strengthening of the material, which resulted in the increase of the yield point while limiting the ability for further plastic deformation. Therefore, brittle fracture occurred at a distance from the edge of the opening. The result of the plastic deformation going from the edge of the hole is visible in the drawing of thinning the sheet in this area. In the case of the rivet version, the described breaking mechanism was uniformly distributed throughout the thickness of the sheet.

Significantly different nature of cracking was observed on the basis of welded fracture surfaces. In this case, the heat affected zone led to structural changes in the metal. Under the influence of the heat generated during welding, the aluminum alloy was unevenly weakened in the cross-section of the sheet thickness. To a certain depth of the plate marked by the border visible in Fig. 8a there was a significant plastic deformation, which had a different character than in the case of the riveted variant. The nature of the fracture is characterized by visible signs of plastic flow of the material as a result of which a ductile fracture was obtained (Fig. 8b). It can be concluded that the heat-affected zone in this area has led to a decrease in the yield point of the material. The area considered is located at the upper surface of the sheet (considering the material arrangement during welding). Below the zone of ductile fracture, the typical fracture for the considered alloy 7075-T6 is similar to the case of the fracture of the riveted sheet. Fig. 8c shows a clear border between two areas with different properties. This situation occurs in the area up to about $4 \mathrm{~mm}$ from the edge of the weld, in the further part of the fracture there was a uniform cracking in the entire sheet thickness (Fig. 8d), as in the riveted variant. 


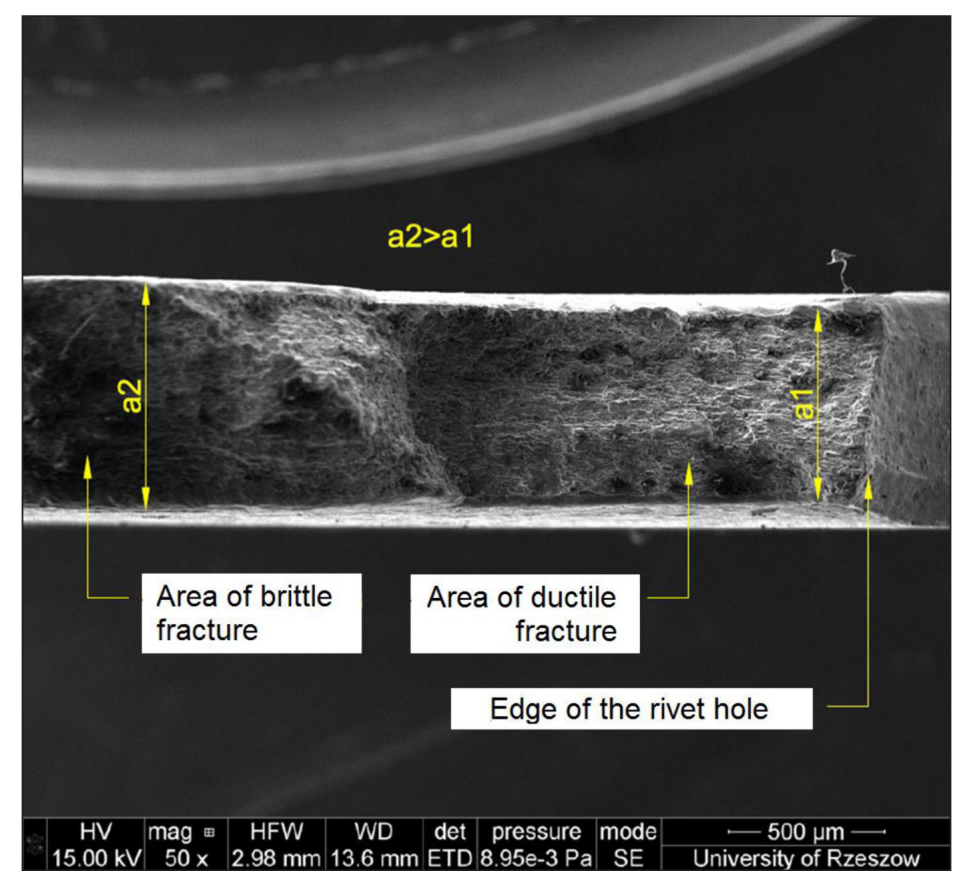

Fig. 7. SEM image of the fracture surface of a sheet weakened by a row of rivets
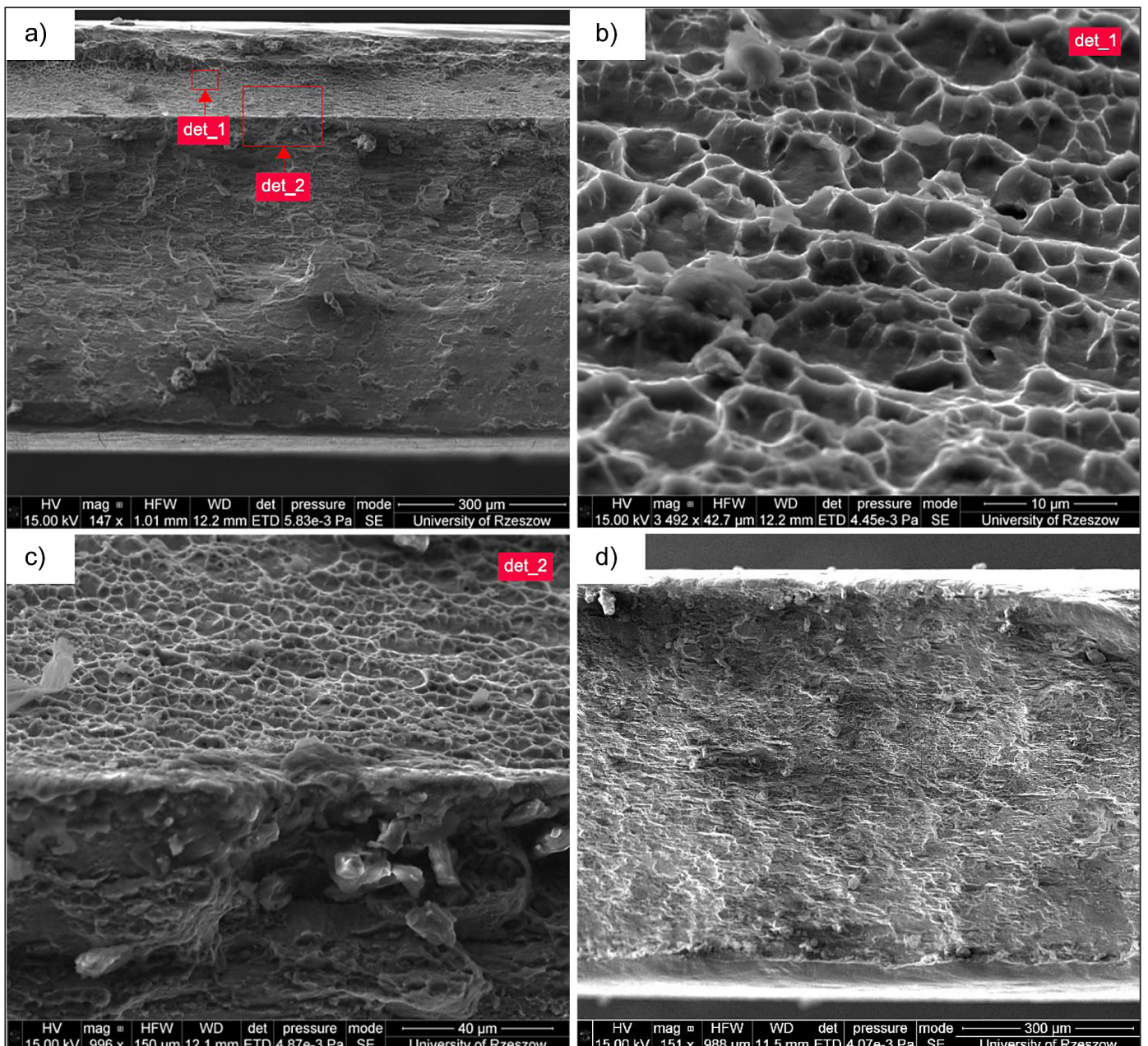

d)

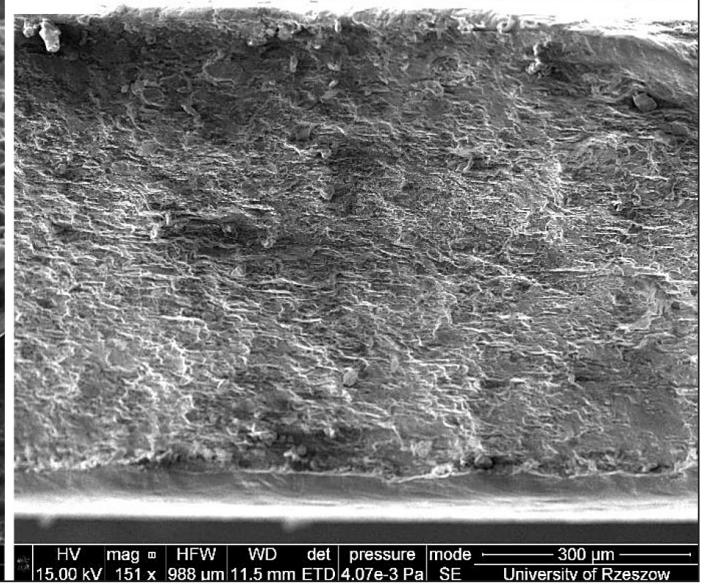

Fig. 8. SEM images of the fracture of the sheet weakened by the RFSSW welds row; view of areas with different properties caused by the heat affected zone (a), enlargement of the area where the ductile fracture occurred (b), enlargement of the boundary between the marked areas (c), view of the fracture from the weld showing uniform material properties $(\mathrm{d})$ 


\section{CONCLUSIONS}

The paper presents the results of experimental studies, which play an important role in the process of implementing a new technology for the production of thin-walled structures. Based on the phenomenon of presurization, the degree of weakening of the skin sheet was demonstrated by a single-row point connection realized with a relatively new technology, which is considered as an alternative method of joining thin-walled stiffened structures. The test results were compared with the results for riveted structures showing a lower degree of weakening of the cover sheet. However, a significant problem related to the direction of cracking of the weakened sheet was demonstrated. In the case of commonly used rivet structures, the cracking path is predictable and runs along rivet holes. However, for the joint welded with the RFSSW method, it was shown that the cracking path may deviate from the weld line and run unpredictably in the structure of the base material.

The presented experimental study should be treated only as a preliminary to further analysis of the phenomenon of weakening the sheet by a welded joint. The very important issue will be fatigue strength, because the actual construction due to the take-land cycles is exposed to periodic stretching. Fatigue tests are planned for future authors' research.

\section{Acknowledgments}

The present work was carried out with the generous support of the Belgian Welding Institute (Zwijnaarde - Gent, Belgium). The authors wish thank dr. ir. Koen Faes for their advice and conducting the welding experiments.

\section{REFERENCES}

1. Aniversario R.B., Harvey S.T., McCarty J.E., Parson J.T., Peterson, D.C., Pritchett L.D., Wilson D.R., Wogulis E.R.: Full-scale testing, production and cost analysis data for the advanced composite stabilizer for Boeing 737 Aircraft. 2, NASA CR-166012, Dec.1982.

2. Bryan H.: Engineering Composite Materials. The Institute of materials, London, Cantwell W.J, Mortont J.: The impact resistance of composite materials - a review. Composites, 1991, 22, 347-362.

3. Deo R., Starnes Jr. J.H., Holzwarth, R.: Low-cost composite materials and structures for aircraft applications. NATO Applied Vehicle Technology Panel (AVT) Specialists' Meeting, RTO-MP069(II), Leon, Norway, May 2001.
4. Cutler J., Liber J.: History, Semi-monocoque structures. Understanding Aircraft Structures, 4th ed., Padstow, Cornwall, Blackwell, 2005, 9-14.

5. Fouse J.A., McClaren S.W.: Airframe assembly and process. United States of America Patent 4, 294, 419, 13 October 1981.

6. Hamamoto K., Amaoka K., Takizawa N., Hosoi M.: Aircraft fuselage structure. Japan Patent 5,170,967, 15 December 1992.

7. Mendez P.F., Eagar T.W.: Welding process for aeronautics. Advanced Materials and Processes, 159, 2001, 39-43.

8. Neye G., Heider P.: Laser beam welding of modern Al-alloy for the aircraft industry. ECLAT'94/Dusseldorf: Deutscher Verband für Schweißtechnik 1994, 108-117.

9. Neye G.: Laserstrahlschweißkonzept für Rumpfschalen-strukturen. Strahltechnik. Band 5, Bremen, Bias-Verlag, Hrsg.: Sepold G, Jüptner W. 1997.

10. Sadowski T., Golewski P.: Skew bending of aircraft fuselage panels with " $\mathrm{L}$ " and "C" stringers mounted by hybrid joint. Archives of Metallurgy and Materials, 60(4), 2015, 2813-2820.

11. Kubit A., Bucior M., Wydrzyński D., Trzepieciński T., Pytel M.: Failure mechanisms of refill friction stir spot welded 7075-T6 aluminium alloy single lap joints. International Journal of Advanced Manufacturing Technology, 94(9-12), 2018, 4479-4491.

12. Hadjez F., Necib B.: Stress Analysis of an Aircraft Fuselage with and without Portholes using CAD/ CAE Process. Journal of Aeronautics \& Aerospace Engineering, 4(1), 2015.

13. Swift T.: Damage tolerance in pressurised fuselages. 11th Plantema Memorial Lecture. New Materials and Fatigue Resistant Aircraft Design (ed. D L Simpson), Engineering Materials Advisory Services Ltd., Warley, UK, 1987, 1-7.

14. Wanhill R.J.H.: Milestone Case Histories in Aircraft Structural Design. National Aerospace Laboratory, NLR-TP-2002-521, 2002.

15. Atkinson R.J., Winkworth W.J., Norris G.M.: Behaviour of Skin Fatigue Cracks at the Corners of Windows in a Comet Fuselage. Reports and Memoranda No. 3248, June, 1960.

16. Phillips E.P., Britt V.O.: Measurements of fuselage skin strains and displacements near a longitudinal lap joint in a pressurized aircraft. NASA Technical Memorandum 104163, October 1991.

17. Kubit A., Kluz R., Trzepieciński T., Wydrzyński D., Bochnowski W.: Analysis of the mechanical properties and of micrographs of refill friction stir spot welded 7075-T6 aluminium sheets. Archives of Civil and Mechanical Engineering, 18(1), 2018, 235-244.

18. ISO 6892-1. ISO 6892-1: Metallic materials - Tensile testing - Part 1: Method of test at room temperature. Standards, 2016, pp. 79. 